January 2019

\title{
Promoting Inclusivity in the Archive: A literature review reassessing tradition through theory and practice
}

Autumn Wetli

Wayne State University, autumnwetli@gmail.com

Follow this and additional works at: https://scholarworks.sjsu.edu/ischoolsrj

Part of the Archival Science Commons

Acknowledgements

\section{Recommended Citation}

Wetli, A. (2019). Promoting Inclusivity in the Archive: A literature review reassessing tradition through theory and practice. School of Information Student Research Journal, 8(2). https://doi.org/10.31979/ 2575-2499.080204 Retrieved from https://scholarworks.sjsu.edu/ischoolsrj/vol8/iss2/4

This article is brought to you by the open access Journals at SJSU ScholarWorks. It has been accepted for inclusion in School of Information Student Research Journal by an authorized administrator of SJSU ScholarWorks. For more information, please contact scholarworks@sjsu.edu. 


\title{
Promoting Inclusivity in the Archive: A literature review reassessing tradition through theory and practice
}

\begin{abstract}
The call for social justice and rise of postmodernism in the second half of the 20th century forced the critical re-evaluation of the traditional archive and its presumed neutral role in the collection and creation of history. Reappraisal of traditional archive theory and practice was forced by heightened critical conscious among the field and its constituents. This literature review examines contemporary methodologies and methods influenced by the postmodern movement and call for social justice in the archive. Affect theory, radical empathy, and queer/ed methodology provide new frameworks for the thinking about the archive space and work towards the creation of a more diverse and inclusive archive. The collection of oral histories and participatory, community archiving practices provide concrete methods for employing the aforementioned theories. This paper purports that these ideas may be better framed within the context of the post-postmodern movement of metamodernism and calls for the continual evaluation of archival theory and practice within this vein.
\end{abstract}

\section{Keywords}

affect theory, radical empathy, queer theory, archives, oral history, community archiving

\section{Acknowledgements}

\section{About Author}

Autumn Wetli has worked at the University of Michigan Library in various capacities since 2013. She graduated with her MLIS from Wayne State University in December 2018. 
In 1970, historian Howard Zinn questioned the supposed neutrality of the archival profession. As part of this critique, Zinn (1977) asserted that the archive is biased towards the collection and preservation of materials produced by, and related to, people deemed important. This bias means "we learn most about the rich, not the poor; the successful, not the failures; the old, not the young; the politically active, not the politically alienated; men, not women; White, not Black; free people rather than prisoners; civilians rather than soldiers; officers rather than enlisted men" (Zinn, 1977, p. 21). Zinn's criticism generated much introspective thought within the profession and subsequent discussion that continued over time. Historian and archivist Randall Jimerson (2007) roused this sentiment again by asserting the moral responsibility of archivists to give equal voice in the archive to those who have been silenced. The Society of American Archivists (2017) now promotes policies intent on increasing and valuing diversity within membership, leadership, the profession, and archival records. This criticism and discussion has resulted in many institutions focusing their appraisal policies on diversifying the archive through the collection of marginalized histories.

It is important to note that while marginalized communities have often lacked representation in the institutional archive, these communities have been actively preserving their own cultures and history outside of the institution. Grassroots African American and gay and lesbian archives provide a few examples of marginalized communities archiving their own histories (Cvetkovich, 2003; Gibbs, 2012). Bringing diverse materials into the archive is not in and of itself an inclusive act, particularly when it can mean just "blindly accessioning records related to a specific race or ethnicity" (Gibbs, 2012, p. 203). Traditional, Western, and Eurocentric standards for appraising, collecting, and processing of archival materials are problematic. To truly address issues of diversity in the archive, the methodologies and methods valued in the profession need to change.

The rise of social activism and postmodern theory in the 1960s forced the archival field to reevaluate its supposed state of neutrality (Ridener, 2009). Postmodernism is an ambiguous, unstable, and difficult concept to define, changing based on who may be discussing it and within what context. Some attributes of postmodernism-the scrutiny of all-encompassing metanarratives, disbelief in communication or knowledge being neutral or unmediated, and a general attack on all forms of authority-are all concepts inherent in a critical rethinking of the archive (Nesmith, 2002; Ridener, 2009). Approaching the archival field with a postmodern view is to be aware of the social construct and power driving institutions and archives. Terry Cook (2001), like others, leans on postmodernism in his call for a shift in archival science focus from product to process, pushing back against the popular "more product, less process" (Greene \& Meissner, 2005). Affect theory, radical empathy, and queer theory are theoretical frameworks that favor a process over the product paradigm and present means to practice a more inclusive, diverse archive. These methodologies reimagine the archive as a space for the collection of feelings rather than just the collection of History with a capital "H." The destruction of archive neutrality not only affects the institution concretely, but also conceptually. 
However, in a contemporary context, it may be more appropriate to push the theoretical embrace of today's archive past the confines of postmodernism. The end of postmodernism has been intermittently heralded since the closing decades of the $20^{\text {th }}$ century, though its death may be better described as a gradual, vacillating shift of ideas which has accelerated since moving into the $2000 \mathrm{~s}$. Metamodernism is one development birthed from the ashes of postmodernism, which is proposed here as a more appropriate means for contextualizing the dynamism that affect theory, radical empathy, and queer theory bring to the archive. These theories value feeling, emotion, and human rights in the archive working in tandem with metamodernism's emphasis on affect, engagement, and storytelling (Levin, 2012). The metamodern focus on consideration and connection more readily describes the social justice work performed in the archive through affect theory, radical empathy, and queer theory.

\section{Theorizing an Inclusive Archive}

Affect, like postmodernism, is an ambiguous and often conflicting term for which no consensus exists (Cifor, 2016; Figlerowicz, 2012). It stages the archive for the collection of feelings. Affect theory addresses concerns integral to thinking critically about the archive, those of representation, identity, accountability, and empowerment (Cifor, 2016). An affective archive better reflects the tumultuous history of marginalized communities than data or demographic records. Soliciting donations of personal, everyday materials is a way to practice affect theory and perform emotional justice in the archive (Cifor, 2016). The Lesbian Herstory Archives (LHA) does so by encouraging a participatory collecting process, which asks for the donation of items any lesbian may consider a critical part of her life (Cvetkovich, 2003). This participatory process empowers marginalized individuals to recognize the value of their histories and asserts the importance of archiving all lives (Cvetkovich, 2003).

In an archive of feelings, archivists must engage empathically with the community they are archiving, entering into a relationship of care with the record creators, the subject of the records, its users, and the larger community (Caswell $\&$ Cifor, 2016). In this sense, the archivist is not indebted to the inanimate record, but rather to the larger human context that is in some way touched by the record. Radical empathy does not erase power dynamics; rather, it forces archivists to be aware of and acknowledge inequalities in the archive (Caswell \& Cifor, 2016). It is not enough for marginalized communities to be heard; instead, they must be heard justly, which reiterates the statement that blindly accessioning materials based on ethnicity or gender does not constitute the building of a diverse archive (Cifor, 2016). For a marginalized community to be heard justly, the archivist must take on an affective responsibility, a caregiver role, providing important emotional, contextual history to the archive. Ignoring the violent and subjugated history of marginalized communities in the archive is just a repetition of these violent acts (Cifor, 2016). The archivist must acknowledge the implications of the institution and the profession in the pain and erasure of marginalized communities and histories.

Queer methodology presents another way to challenge dominant

paradigms in the archive. Queerness can be characterized as indeterminate and 
fluid, aligning itself with earlier discussions surrounding the instability of the postmodern and metamodern archive (Jagose, 1996). Queer theory examines the concept of identity and its supposed stability, exposing the fragile construct of identity (Watson, 2005). It is another framework for pushing back against historical and cultural elements that may be declared the "norm" (Watson, 2005). This question and struggle with identity is not limited to mainstream society but can also be an issue in marginalized communities. For example, limiting an identity to the label of "gay" or "lesbian," "heterosexual" or "homosexual," denies the layered and multifaceted identities of many individuals.

Jamie Ann Lee's (2017) Queer/ed archival methodology places the dynamic principles of queer theory in juxtaposition to the idea of a fixed and stable archive. Abbreviated as $\mathrm{Q} / \mathrm{M}$, this methodology reacts against the traditional archive through an unhinging of hierarchical knowledge. $\mathrm{Q} / \mathrm{M}$ places emphasis on the imagination of an archival space that can hold competing histories, even those outside of the archivist's known perspective (Lee, 2017). Oral histories in the Arizona Queer Archives presents examples of these competing histories, showcasing the multiple identities queer bodies can be associated with and emphasizing the nomadic and metamorphic possibilities of both queer and archival bodies (Lee, 2017). Q/M is based on seven principles: a participatory ethos, connectivity, storytelling, intervention, reframing, reimagining, and flexibility/dynamism (Lee, 2017). Though exact terminology and definitions may vary, these focuses are similarly reflected through an affect archive and the act of radical empathy. The malleability of the queer/ed archive allows for the collection of contradictory, lived histories and continual, evolving metamorphosis in the archive. Affect theory, radical empathy, and queer theory mark the archive as a space inseparable from social justice and politics. These methodologies value emotion and are in direct contrast to the traditional archive field, which is rooted in the scientific, objective, and unemotional facts.

Approaching the field with new theoretical frameworks helps to address issues of diversity in the archive, but inclusive practices are also essential to complement theory.

\section{Practicing an Inclusive Archive}

\section{Valuing Oral Histories}

Oral histories play an important role in bringing affect and queer methodology into the archive. While oral history has not always been valued as a form of historical record, its appreciation in the archive has grown within the past decades (Erdmans, 2007). Oral histories defy the traditional and scientific methods often used for historic preservation. Narratives allow for sentimentality, often negatively viewed as non-objective and unscientific. At the same time, however, sentimentality allows deeper meanings to be created in the archive (Erdmans, 2007). Oral history lends itself to the affective, to a state of practicing radical empathy and a feminist ethics of care with its subjects. E. Patrick Johnson (2016), a cisgender, Black gay man collecting the stories of cisgender Black queer women, focused his research on oral histories because through "the act of performing one's life history, the self is affirmed through the interaction with 
another who bears witness to the story being told" (p. 63). Collecting oral histories as artifacts in the archive allows for increased inclusivity and more diverse representations in the archive (Johnston, 2001).

In order to embrace oral history, researchers must first accept its inherently subjective nature (Erdmans, 2007). A handful of narratives may not accurately summarize a distinct lived experience, while at the same time, an archival space may hold competing stories (Erdmans, 2007). Queer theory's application to oral history means reading the narrator's voice in a similar manner to the way one would read a text, open to interpretation (Boyd, 2008). As queer theory supports, arriving at one, all-encompassing lived experience, proclaimed as fact and history, should not be the goal of the archive. The conflict and fluidity oral histories provide the archive better represent the reality of lived human experience and align with metamodern characteristics of oscillation. Similarly, the written word, heralded as truth, must be acknowledged as coming from a position of privilege. The Western world's emphasis on the written word as a testament of history is not universally practiced or praised by all cultures. Rejecting oral history as a valid part of historical collections is a rejection of cultures where literacy and written records do not figure prominently. Nevertheless, these cultures may offer rich, well-endowed oral traditions (Hagan, 1978; Johnston, 2001).

The Houston Metropolitan Research Center (HMRC), housed in the city's public library, relies heavily on oral histories as an integral component of the archive (Kreneck, 1985). In some instances, oral histories may be the only way to document an event that only still exists through memory (Kreneck, 1985). For example, theWoodmen of the World, one of Houston's earliest MexicanAmerican community institutions, lacks records and documentation (Kreneck, 1985). Through interviews with some of its first members, archivists were able to shed light on the organization and its mission (Kreneck, 1985). The HMRC project made a conscious effort to supplement all items in the collection with oral histories, bestowing oral histories with as much importance as the physical records in the collection.

\section{Community Archiving}

Scholar's view archives as the custodial spaces of history and its artifacts, a model which predicates ownership, power, and control. To negate this, many organizations have moved towards a model of stewardship. These institutional archives work cooperatively with the communities whose histories they are preserving by providing stable infrastructure, training, and technological support.

The University of Texas Libraries (UTL) Human Rights Documentation Initiative works under a stewardship model, and as an archive created to preserve and provide access to records about human rights conflicts, is responsible for practicing affect, radical empathy, and a feminist ethics of care in the archive. Initially, organizations, composed of both national and international groups, were hesitant to give up documents of intense symbolic and memorial value (Kelleher, 2017). Organizations recognized the benefits UTL could offer in regards infrastructure and funding, but the value of these documents to local communities was not something that could be easily dismissed. Collaboration under a 
stewardship model created an environment that was able to better support and benefit everyone involved. UTL was flexible in its stewardship role, customizing practices to the different needs and desires of the various organizations. While some organizations wanted their materials to remain directly in UTL's care, others wanted to be their own archival repositories. For organizations of the latter type, UTL provided the funding and training (for the care and digitization of collections) directly to organizations and their local communities, while UTL accepted digital surrogates of materials for their repository (Kelleher, 2017).

Despite a more collaborative approach, this work is not without contention. The institution struggled with images representing human rights victims and survivors. While UTL gathered permission for use of these images from human rights organizations, they were unable to enter into a dialogue regarding use with the individual subjects or families of those reflected in the images (Kelleher, 2017). Procedures have been changed to use such materials less frequently, but use has not stopped altogether (Kelleher, 2017). Critical to the practice of radical empathy in the archive is UTL's continual reflection and examination of the actions and motives in the archive.

The HMRC project (1985) relied heavily on community participation during the archival process. Many of the materials the HMRC sought were of a personal or ephemeral nature, privately held by families and individuals in the community (Kreneck, 1985). The personal nature of these materials made community outreach crucial for the collection of archival materials. Gaining the trust of the community was a difficult task, as under the status quo, marginalized communities are often the victims of domination and subjugation. Partnering with local Houston media, particularly focused on the Mexican-American community, the HMRC was able to solicit community volunteers to help with technical abilities, like Spanish language skills, and garner more community support for the program (Kreneck, 1985). Engaging volunteers from the community in this manner builds trust and helps break through a community's often well-founded insularity (Johnston, 2001). Collaborative archiving does not always have to take place within the institutional archive. Many grassroots community archives are located in makeshift or do-it-yourself (DIY) spaces.

Community archives are symbolic, as they create a fixed space for communities that were often unwelcome and pushed out of mainstream spaces. These spaces then become an assertion of the community's rights to existence and validation of their history (Caswell, Gabiola, Zavala, Brilmyer, \& Cifor, 2018). No matter where a community archive is situated, it should not be entirely driven by its physical space, but by the community's involvement (Stevens, Flinn, \& Shepherd, 2010). The support of volunteers motivated by political activism and community engagement is a testament to the importance of community archives.

Community archives built outside of mainstream institutions can provide a feeling of home and comfort to researchers and community members (Caswell et al., 2018). They are described by users as spaces that provide a sense of belonging (Caswell et al., 2018). Many grassroots gay and lesbian archives began in the safe and intimate space of individual homes (Cvetkovich, 2003). Queer identifying archivist Marika Cifor (2016) describes her experience entering the Lesbian 
Herstory Archives for the first time as "one of her most powerful archival encounters" (p. 38). This homey welcome into the archive, which in the instance of the LHA is literally inside the caretaker's home, is situated within the practices of affect theory. It establishes the archive as a space for feeling and emotion over just providing space for an intellectual transaction (Caswell \& Cifor, 2016).

Visibility and access are often of vital importance in community archives; the Beamish Museum in England provides preservation and storage for community collections without impinging on the community's ownership or access. "Heritage cubes" are available to local organizations in addition to a shared collection study room and trainings on collection care (Stevens et al., 2010 , p. 65). These heritage cubes are only accessible by the public or the museum with permission from local organizations, placing power and control in the hands of the organization, not the institution.

The collection of oral histories and engagement in community archiving practices are two ways to work towards a more diverse, inclusive, and participatory archive. The concept of a participatory archive is crucial for implementing and practicing affect theory, radical empathy, and queer theory in the archive. Working cooperatively with communities presents unique challenges to the traditional archive and archivist but provides direct action to combat the subjugation of marginalized histories. Flexibility and adaptability present themselves as characteristics key to the creation of a diverse and inclusive archive, which relies heavily on the transitory nature of contemporary, metamodern thought.

\section{Conclusion}

Ultimately, the archival field must decide what is at stake when clinging to traditional theories and processes and whether it is worth it to shift to a model emphasizing a more engaging and inclusive process over the product itself. If the archival field is committed to promoting diversity and inclusion in the archive, it must wholly embrace emerging and evolving theories and practices that deviate from tradition. Critical thinking has led to a deeper awareness of bias in the field and has promulgated some positive change. Siding with the argument that the postmodern moment has passed, the methodologies and methods for archival practice presented in this paper should be considered in the context of new and evolving theoretical thought. The activist archivist fits more appropriately within the sincere and pragmatic idealism presented in the contemporary paradigm of metamodernism than the apathy, disaffection, and cynicism of postmodernism (Vermeulen \& Akker, 2010; Akker \& Vermeulen, 2017).

The definition of "meta," as "with," "between," and "beyond," befittingly depicts the oscillating nature of the methodologies and methods presented in this paper. Metamodernism fluctuates between the enthusiasm of the modern and the irony of the postmodern (Vermeulen \& Akker, 2010). An aware archive, focused on the promotion of social justice, is aware of its flaws and biases, while still being hopeful and forward-looking. Not contemplating the archive outside of postmodern thought would mean a resignation to its inequalities. Future and continuing research should place the archive within metamodern thought. The discussion of archival theory and practice evolving over the past few decades has 
pushed the field beyond an acceptance of inequality towards a critically conscious, politically active archive space, which will only continue to challenge the hierarchy established by the traditional status quo.

\section{References}

Akker, R. \& Vermeulen, T. (2017). Periodising the 2000s, or, the emergence of metamodernism. In R. Akker, A. Gibbons, \& T. Vermeulen (Eds.), 
Metamodernism: Historicity, affect, and Depth after postmodernism (pp. 1-19). Rowman \& Littlefield.

Boyd, N. A. (2008). Who is the subject? Queer theory meets oral history. Journal of the History of Sexuality, 17, 177-189. Retrieved from https://www.jstor.org/stable/30114216

Caswell, M. \& Cifor, M. (2016). From human rights to feminist ethics: Radical empathy in the archives. Archivaria, 81, 23-41. Retrieved from https://archivaria.ca/index.php/archivaria/article/view/13557

Caswell, M., Gabiola, J., Zavala, J., Brilmyer, G., \& Cifor, M. (2018). Imagining transformative spaces: The personal-political sites of community archives. Archival Science, 18, 73-93. https://doi.org/10.1007/s10502-018-9286-7

Cifor, M. (2016). Affecting relations: Introducing affect theory to archival discourse. Archival Science, 16, 7-31. https://doi.org/10.1007/s10502$\underline{015-9261-5}$

Cook, T. (2001). Fashionable nonsense or professional rebirth: Postmodernism and the practice of archives. Archivaria, 51, 14-35. Retrieved from https://archivaria.ca/archivar/index.php/archivaria/article/view/12792

Cvetkovich, A. (2003). In the archive of lesbian feelings. In An archive of feelings (pp.239-271). Durham, NC: Duke University Press.

Erdmans, M. P. (2007). The personal is political, but is it academic? Journal of American Ethnic History, 26(4), 7-23. Retrieved from http://www.jstor.org/stable/40543197

Figlerowicz, M. (2012). Affect theory dossier: An introduction. Qui Parle: Critical Humanities and Social Sciences, 20, 3-18. Retrieved from https://muse.jhu.edu/article/475025

Gibbs, R. (2012). The heart of the matter: The developmental history of African American archives. The American Archivist, 75, 195-204. https://doi.org/10.17723/aarc.75.1.n1612w0214242080

Greene, M. A. \& Meissner, D. (2005). More product, less process: Revamping traditional archival processing. The American Archivist, 68, 208-263. Retrieved from https://www.jstor.org/stable/40294290

Hagan, W. T. (1978). Archival captive-The American Indian. The American Archivist, 135-142. 
Retrieved from http://www.jstor.org/stable/40292079

Jagose, A. (1996). Queer theory: An introduction. New York: New York University Press.

Jimerson, R. (2007). Archives for all: Professional responsibility and social justice. The American Archivist, 70, 252-281. https://doi.org/10.17723/aarc.70.2.5n20760751v643m7

Johnson, E. P. (2016). Put a little honey in my sweet tea: Oral history as quare performance. WSQ: Women's Studies Quarterly, 44(3/4), 51-67. Retrieved from https://muse.jhu.edu/article/632146/pdf

Johnston, I. (2001). Whose history is it anyway? Journal of the Society of Archivists, 22, 213-229. https://doi.org/10.1080/00379810120081154

Kelleher, C. (2017). Archives without archives: (Re)locating and (re)defining the archive through post-custodial praxis. Critical Archive Studies, 1(2), 1-30. https://doi.org/10.24242/jclis.vli2.29

Kreneck, T. (1985). Documenting a Mexican American community: The Houston example. The American Archivist, 48, 272-285. https://doi.org/10.17723/aarc.48.3.171t58027k165340

Lee, J. A. (2017). A queer/ed archival methodology: Archival bodies as nomadic subjects. Critical Archive Studies, 1(2), 1-27. https://doi.org/10.24242/jelis.v1i2.26

Levin, K. (2012, October 15). How PoMo can you go? ARTnews. Retrieved from http://www.artnews.com/2012/10/15/howpomo-can-you-go/

Nesmith, T. (2002). Seeing archives: Postmodernism and the changing intellectual place of archives. The American Archivist, 65, 24-41. Retrieved from https://www.jstor.org/stable/40294187

Ridener, J. (2009). From polders to postmodernism. Sacramento, CA: Litwin Books.

Society of American Archivists. (2017, November 11). SAA diversity and inclusion initiatives. Retrieved from https://www2.archivists.org/advocacy/diversity-and-inclusion-initiatives

Stevens, M., Flinn, A., \& Shepherd, E. (2010). New frameworks for community engagement in the archive sector: From handing over to handing on. 
International Journal of Heritage Studies, 16, 59-76. https://doi.org/10.1080/13527250903441770

Vermeulen, T. \& Akker, R. (2010). Notes on metamodernism. Journal of Aesthetics \& Culture, 2(1), 1-14. https://doi.org/10.3402/jac.v2i0.5677

Watson, K. (2005). Queer theory. Group Analysis, 38, 67-81. https://doi.org/10.1177/0533316405049369

Zinn, H. (1977). Secrecy, archives, and the public interest. The Midwestern Archivist, 2, 14-26. Retrieved from https://minds.wisconsin.edu/handle/1793/44118 